whose state was less and less a consequence of personal handicap and more and more the outcome of impersonal, economic factors. It is a moot point whether in times of mass unemployment handicap at an individual level continues to be of much significance. ${ }^{11}$ The incidence of parasuicide among the unemployed, however, always remained dramatically higher than among the employed and only once in the years 1976-82 was the relative risk less than 10-fold (table I). For clarity we would emphasise that the decline in the incidence of parasuicide among the unemployed has been more than offset by the increase in their numbers. The population attributable risk has shown a tendency to rise in line with the upward trend in unemployment despite the decline in relative risk (table I), and the proportion of the overall rate attributable to unemployment increased from $36.5 \%$ in 1979 to $57.8 \%$ in 1982 (table I). We will shortly report more detailed estimates.

Our third notable finding was the role of long term unemployment. After one year the risk approached double that for shorter periods. Such a relation is of course in line with the hypothesis that unemployment is a cause of parasuicide, though other interpretations are (just) possible. But whether unemployment is directly causal or not, the association of parasuicide with chronic unemployment is clear. That about $45 \%$ of men unemployed at present have been out of work for over a year and that this figure is forecast by the Manpower Services
Commission to climb even higher in the next few years is particularly disturbing. The prospect in terms of both personal distress and future incidence of parasuicide is ominous.

\section{References}

1 Platt SD. Unemployment and suicidal behaviour: a review of the literature. Soc Sci Med 1984;19:93-115.

Hawton K, O'Grady J, Osborn M, Cole D. Adolescents who take overdoses: their characteristics, problems and contact with helping agencies. $\mathrm{Br}$ Psychiatry 1982;140:118-23.

Kessell A, Nicholson A, Graves G, Krupinski J. Suicidal attempts in an outer egion of metropolitan Melbourne and in a provincial region of Victoria. Aust NZ F Psychiatry 1975;9:255-61.

Forrest $\mathrm{A}$, ed $A$ companion to psychis of suicide and attempted suicide. In Livingstone, 1973:38-63.

5 Bancroft J, Skrimshire A, Reynolds F, Simkin S, Smith J. Self-poisoning and selfinjury in the Oxford area: epidemiological aspects 1969-73. British fournal of Preventive and Social Medicine 1975;29:170-7.

6 Buglass D, Duffy JC. The ecological pattern of suicide and parasuicide in Edinburgh. Soc Sci Med 1978;12:241-53.

7 Bagley C, Jacobson S, Palmer C. Social structure and the ecological distribution of mental illness, suicide and delinquency. Psychol Med 1973;3:177-87.

8 Kreitman N, ed Parasuicide. London: Wiley, 197

Kennedy P, Kreitman N. An epidemiological survey of parasuicide ("attempted suicide") in general practice. Br f Psychiatry 1973;123:23-34. uglass $\mathrm{D}$, Duffy JC, Kreitman N.A register of social and medical indices by local government area in Edinburgh and the
Research Unit, Scottish Office, 1980 .

11 White M. Long-term unemployment and labour markets. London: Policy Studies Institute, 1983.

(Accepted 8 August 1984)

\title{
Spectinomycin as initial treatment for gonorrhoea
}

\author{
C S F EASMON, G E FORSTER, G D WALKER, C A ISON, J R W HARRIS, P E MUNDAY
}

\begin{abstract}
The prevalence of penicillinase producing Neisseria gonorrhoeae at this hospital increased exponentially from $<0.5 \%$ in 1978 to $6.5 \%$ of all isolates in 1982 . In January 1983 first line treatment for uncomplicated heterosexual anogenital gonorrhoea was therefore changed from ampicillin and probenecid to spectinomycin. This subsequently cured $95 \%$ of cases seen at the Praed Street Clinic. Although there was an initial fall in the monthly isolation rate of penicillinase producing $\mathbf{N}$ gonorrhoeae after the introduction of spectinomycin, this was not maintained. The exponential increase in the prevalence of the strain did slow in 1983 , rising to only $8.7 \%$. This, however, may have reflected a general decline in the rate of increase of penicillinase producing $N$ gonorrhoeae throughout Britain.
\end{abstract}

The failure to influence the prevalence of penicillinase

\footnotetext{
Department of Medical Microbiology, St Mary's Hospital Medical School, London W2 1PG

C S F EASMON, MD, PHD, professor

C A ISON, MSC, chief medical laboratory scientific officer

Department of Venereology, St Mary's Hospital, London W2 1PG G E FORSTER, MRCOG, senior registrar

G D WALKER, MB, BS, research senior house officer

J R W HARRIS, MRCP, DTM\&H, consultant

P E MUNDAY, MD, MRCOG, honorary consultant

Correspondence to: Professor C S F Easmon.
}

producing $\mathbf{N}$ gonorrhoeae to any great degree may have been due in part to spectinomycin resistance in both penicillinase producing and non-penicillinase-producing N gonorrhoeae. All of the isolates appeared identical, apart from the presence of the 4.4 megadalton plasmid in penicillinase producing $\mathbf{N}$ gonorrhoeae, but they could not be linked epidemiologically. Changing treatment in only one of the many venereal diseases clinics in London, where patients have open access to all such clinics, is unlikely to affect the prevalence of penicillinase producing $\mathbf{N}$ gonorrhoeae. This has probably been more important than spectinomycin resistance in limiting the effectiveness of spectinomycin in reducing the prevalence of the strain.

\section{Introduction}

Penicillin has been the mainstay of treatment for gonorrhoea since the 1940 s but is inactive against penicillinase producing Neisseria gonorrhoeae, which first appeared in $1976 .{ }^{12}$ Gonorrhoea caused by that strain necessitates treatment with penicillinase stable antibiotics. McCutchan et al and McCormack suggested that a penicillinase stable antibiotic should be used as first line treatment for gonorrhoea when the prevalence of penicillinase producing $N$ gonorrhoeae exceeded $5 \%{ }^{34}$ Thus in January 1983 spectinomycin was introduced as first line treatment for uncomplicated anogenital gonorrhoea in women and heterosexual men attending the Praed Street Clinic at this hospital.

We report the effect of spectinomycin on the prevalence of penicillinase producing $N$ gonorrhoeae in a large open access clinic for sexually transmitted diseases and summarise our clinical, epidemiological, and laboratory experience with spectinomycin resistant $N$ gonorrhoeae. 


\section{Patients and methods}

Until the end of 1982 cases of urethral and cervical gonorrhoea were treated with oral ampicillin $(3.5 \mathrm{~g})$ and probenecid $(1 \mathrm{~g})$. Patients allergic to penicillin were treated with spectinomycin $(2 \mathrm{~g})$ intramuscularly. Homosexual men with rectal infections were treated with co-trimoxazole in a multidose regimen for 48 hours. During 1982 trials of cefoperazone $(0.5 \mathrm{~g})$ and amoxycillin-clavulanic acid (Augmentin; $3.25 \mathrm{~g}$ ) were conducted.

After 1 January 1983 women and heterosexual men with gonorrhoea were treated with spectinomycin $(2 \mathrm{~g})$. Since penicillinase producing $N$ gonorrhoeae was rarely isolated from homosexual men and since spectinomycin is considerably more expensive than ampicillin and probenecid or co-trimoxazole, a decision was made to continue these treatments for homosexually acquired gonorrhoea. For various reasons a few patients were given other agents, including tetracyclines and erythromycins, both before and after 1 January 1983.

$N$ gonorrhoeae was isolated on gonococcal agar base (Difco) supplemented with $1 \%$ IsoVitalex (BBL) and made selective by the addition of vancomycin, colistin, trimethoprim, and amphotericin B. Samples were inoculated directly on to the media in the clinic and incubated at $36^{\circ} \mathrm{C}$ in $7 \% \mathrm{CO}_{2}$ before and after transportation to the laboratory. After $\mathbf{4 8}$ hours of incubation colonies were identified by their Gram stain, oxidase reaction, and ability to utilise glucose but not maltose, lactose, or sucrose. Activity of $\beta$-lactamase was determined by the chromogenic cephalosporin test (nitrocefin), and resistance to spectinomycin using an agar diffusion test with a $100 \mu \mathrm{g}$ disc.

Plasmids were analysed using the rapid technique of Birnboim and Doly, ${ }^{5}$ samples being electrophoresed in $1 \%$ agarose in $0.02 \mathrm{M}$ sodium acetate buffer $\mathrm{pH} 7.8$ and visualised using ethidium bromide. Auxotyping was performed using the method of Catlin. ${ }^{6}$ Determination of serovars with monoclonal antiprotein I antibodies was performed by coagglutination, as described. ${ }^{7}$

\section{Results}

Between 1978 and 1982 the prevalence of penicillinase producing $N$ gonorrhoeae at the hospital rose exponentially to $6.5 \%$ (fig 1 ). In 1983 ,

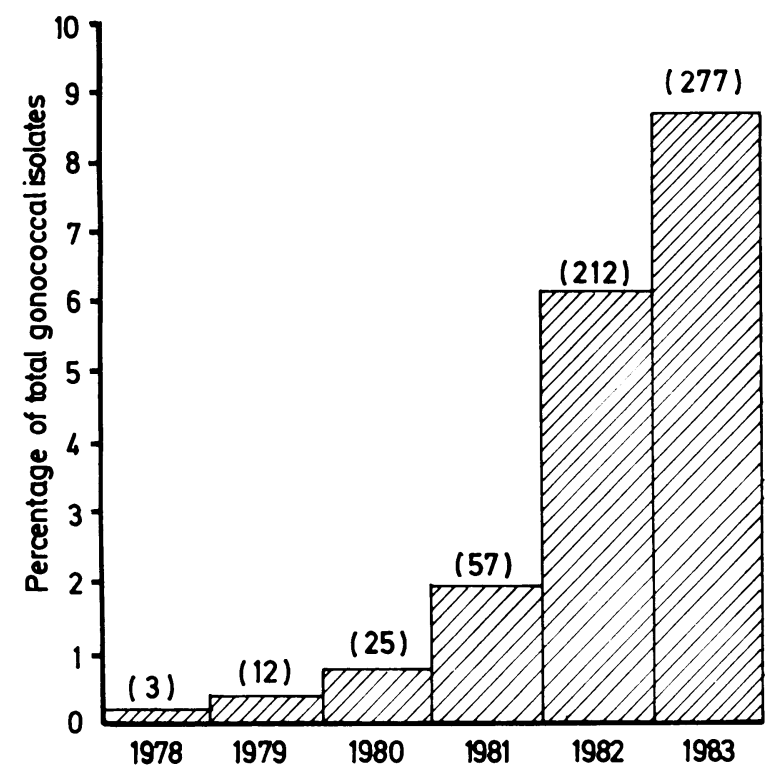

FIG 1-Prevalence of penicillinase producing $N$ gonorrhoeae during 1978-83. (Total number of isolates in parentheses.)

however, the prevalence rose to only $8.7 \%$ as opposed to the $13 \%$ that would have been expected had the trend from earlier years been maintained. The introduction of spectinomycin in January 1983 was followed by a steady fall in the monthly isolation rate of the strain during the first half of that year (fig 2). Unlike in Los Angeles this was not maintained. ${ }^{8}$ The question therefore arose whether spectinomycin resistance in penicillinase producing $N$ gonorrhoeae, first seen at the hospital in 1981, had contributed to our failure to influence the prevalence of the strain to a greater degree.
Although eight spectinomycin resistant strains of penicillinase producing $N$ gonorrhoeae ( $3 \%$ of all isolates) had been seen before the introduction of spectinomycin as first line treatment, a further 14 patients $(5 \%)$ infected with these strains were seen during 1983 . The table gives the details of these patients. In 11 of the 22 patients resistant strains were isolated after initial spectinomycin treatment in our clinic, for nine of which pretreatment isolates were known to be sensitive to spectinomycin. In 11 patients a spectinomycin resistant strain was isolated at their first visit to the clinic before treatment. Five of these patients were known sexual contacts of patients with gonorrhoea caused by spectinomycin resistant penicillinase producing $N$ gonorrhoeae.

We have also encountered spectinomycin resistance in nonpenicillinase-producing $N$ gonorrhoeae. Before we changed to spectinomycin the incidence of resistance in non-penicillinase-producing $N$ gonorrhoeae was unknown, as until then we had screened only penicillinase producing $N$ gonorrhoeae. During 1983 we tested 2933 isolates of non-penicillinase-producing $N$ gonorrhoeae and detected six that were resistant to spectinomycin $(0 \cdot 2 \%)$, although the first example was not seen until August. Since January 1984 we have isolated a further eight spectinomycin resistant strains of non-penicillinaseproducing $N$ gonorrhoeae.

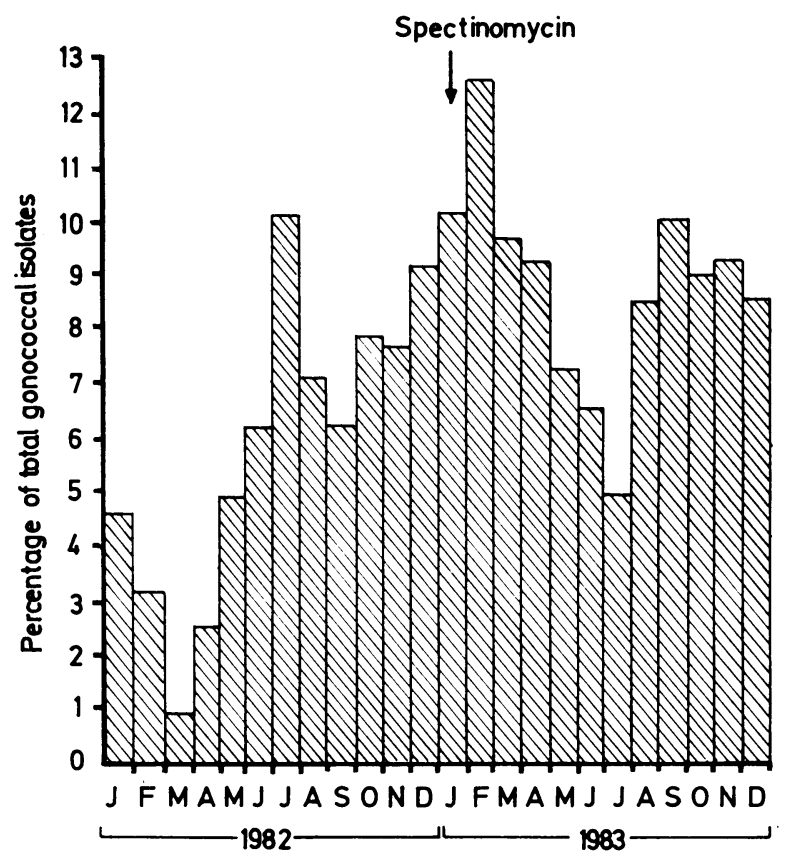

FIG 2-Monthly isolation rate of penicillinase producing $N$ gonorrhoeae during 1982 and 1983. (Treatment changed from ampicillin and probenecid to spectinomycin in January 1983.)

Spectinomycin resistant penicillinase producing $N$ gonorrhoeae: clinical and epidemiological dato

\begin{tabular}{|c|c|c|c|c|c|}
\hline Isolate No & Date of isolation & Sex & Age & Source & $\begin{array}{l}\text { Developed } \\
\text { resistance } \\
\text { during } \\
\text { treatment }\end{array}$ \\
\hline $\begin{array}{c}1 \\
2^{*} \\
3^{*} \\
4 \\
5 \\
6 \\
7 \\
8 \\
9 \\
10 \\
11 \\
12 \\
13 \dagger \\
14 \dagger \\
15 \\
16 \\
17 \\
18 \\
19 \ddagger \\
20 \\
21 \ddagger \\
22 \ddagger\end{array}$ & $\begin{array}{l}\text { November } 1981 \\
\text { September } 1982 \\
\text { September } 1982 \\
\text { September } 1982 \\
\text { October } 1982 \\
\text { October } 1982 \\
\text { November } 1982 \\
\text { November } 1982 \\
\text { January } 1983 \\
\text { February } 1983 \\
\text { February } 1983 \\
\text { February } 1983 \\
\text { March } 1983 \\
\text { March } 1983 \\
\text { March } 1983 \\
\text { March } 1983 \\
\text { March } 1983 \\
\text { March } 1983 \\
\text { April } 1983 \\
\text { May } 1983 \\
\text { May } 1983 \\
\text { October } 1983\end{array}$ & $\begin{array}{l}M \\
M \\
F \\
M \\
M \\
F \\
F \\
M \\
F \\
M \\
F \\
M \\
F \\
M \\
M \\
M \\
F \\
F \\
F \\
M \\
M \\
M\end{array}$ & $\begin{array}{l}27 \\
44 \\
20 \\
22 \\
26 \\
21 \\
29 \\
20 \\
20 \\
24 \\
20 \\
22 \\
19 \\
19 \\
23 \\
27 \\
20 \\
18 \\
29 \\
45 \\
39 \\
32\end{array}$ & $\begin{array}{l}\text { UK } \\
\text { ”, } \\
\text { ”, } \\
\text { ”, } \\
\text { ”, } \\
\text { ”, } \\
\text { ”, } \\
\text { ”, } \\
\text { ”, } \\
\text { ” }\end{array}$ & $\begin{array}{l}+ \\
+ \\
+ \\
+ \\
+\end{array}$ \\
\hline
\end{tabular}

$*+$ Known sexual partners. 
All the spectinomycin resistant $N$ gonorrhoeae required proline for growth and carried the 2.6 and 24.5 megadalton plasmids. The penicillinase producers also carried the $\mathbf{4 . 4}$ megadalton plasmid. All strains showed high level resistance to spectinomycin $(\geqslant 512 \mathrm{mg} / \mathrm{l})$. Two of these were not detected on initial screening with a $100 \mu \mathrm{g}$ spectinomycin disc, and the other resistant strains grew up to the disc. Serological studies showed that all spectinomycin resistant $N$ gonorrhoeae tested were indistinguishable. The serovar was Bacjk.

Despite the biological similarity among the strains they were isolated over a long period, and, although three contact pairs were seen, no clear overall epidemiological pattern was evident.

Clinical failure with spectinomycin that could not be accounted for by spectinomycin resistance occurred in $5 \%$ of patients, a figure compatible with other treatment regimens employed at the clinic. ${ }^{9}$

\section{Discussion}

The change from oral treatment to intramuscular spectinomycin did not prove to be a major problem, and by September 1983 some $85 \%$ of heterosexual patients with gonorrhoea were receiving spectinomycin. In common with others we have isolated few examples of penicillinase producing $N$ gonorrhoeae $(14 / 588)$ from male homosexuals ${ }^{10}$ and consequently ampicillin and probenecid remained first line treatment for these patients. Some 2000 patients received spectinomycin in 1983.

In Los Angeles the introduction of spectinomycin combined with intensive epidemiological back up had a spectacular effect in reducing the prevalence of infections with penicillinase producing $N$ gonorrhoeae. ${ }^{8}$ We have seen no such effect, but there are important differences between the two settings. Firstly, the Praed Street Clinic is only one of many clinics in London for sexually transmitted diseases. Patients have ready access to all public clinics and can and do go from one to another. In this setting a change in treatment in one clinic, albeit the largest one, can have only a limited effect. Secondly, we do not have the financial resources to carry out intensive epidemiological work on the scale done in Los Angeles. We believe that this aspect is at least as important as the introduction of a penicillinase stable antibiotic.

If spectinomycin has not caused a dramatic fall in the prevalence of penicillinase producing $N$ gonorrhoeae, has it prevented a dramatic rise? The increase in numbers of penicillinase producing $N$ gonorrhoeae isolated yearly did slow down in 1983 after the dramatic rise during the previous five years. A similar pattern, however, was evident in the figures for penicillinase producing $N$ gonorrhoeae isolated in England and Wales. During July to December 1983 there were 599 isolates of penicillinase producing $N$ gonorrhoeae reported to the Communicable Disease Surveillance Centre. This compares with 624 in the preceding six months and 613 during July to December 1982. "1 It will be several months, however, before we know whether the same is true world wide.

Spectinomycin resistance in both penicillinase producing and non-penicillinase-producing gonococci has been a worrying development, but despite sporadic reports in Britain and a cluster of cases in Korea there is no evidence of dissemination of strains world wide. Although our early isolates of penicillinase producing $N$ gonorrhoeae were all directly linked to spectinomycin treatment, we have since seen the apparent transmission of these organisms. Microbiological evidence suggests that we are dealing with a single clone of organisms, but we lack the epidemiological information to link them. Apart from possession of the 4.4 megadalton plasmid coding for penicillinase production, all the spectinomycin resistant $N$ gonorrhoeae are so similar that they may well have a common source. This might be either a strain of penicillinase producing $N$ gonorrhoeae that has lost its 4.4 plasmid or a strain of non-penicillinase-producing $N$ gonorrhoeae that has gained it. The serological evidence also supports a common source. It is also possible, howeverthough highly unlikely-that we are observing a series of unconnected events.

We changed to spectinomycin as first line treatment using the principle suggested by McCutchan et al and McCormack that this should be done if the prevalence of penicillinase producing $N$ gonorrhoeae rose above $5 \%{ }^{3}{ }^{4}$ Spectinomycin when used as first line treatment successfully cured $95 \%$ of all gonorrhoea at the Praed Street Clinic. Continued treatment with ampicillin and probenecid would have necessitated further treatment for all infections with penicillinase producing $N$ gonorrhoeae $(8.7 \%)$ together with an additional $5 \%$ of non-penicillinase-producing $N$ gonorrhoeae infections (unpublished data). This overall failure rate of at least $14 \%$ justifies our policy of continuing to use a penicillinase stable drug, although these are some six times more expensive than ampicillin and probenecid. We do not believe, however, that the introduction of such a drug into a single clinic in a large metropolitan area such as London, served by many clinics, can influence the prevalence of penicillinase producing $N$ gonorrhoeae either in that clinic population or in the population at large. Therefore, given these special circumstances in London, we must question the relevance of the $5 \%$ level.

Recently Thin et al commented that a penicillinase stable cephalosporin such as cefotaxime was preferable to spectinomycin for the treatment of infections caused by penicillinase producing $N$ gonorrhoeae. ${ }^{12}$ They based this on the emergence of spectinomycin resistance and on two clinical failures of spectinomycin that occurred despite in vitro sensitivity. Our overall clinical failure rate of $5 \%$ with spectinomycin is comparable with other regimens for gonorrhoea. Any resistance of $N$ gonorrhoeae is worrying and needs careful monitoring. To date, however, we do not think that spectinomycin resistance among strains of $N$ gonorrhoeae is a major clinical problem either at St Mary's Hospital or elsewhere in Britain. If the routine use of spectinomycin is not accompanied by careful follow up and screening of all gonococcal isolates, once resistance has occurred it could build up to serious levels very rapidly.

We thank Dr E G Sandstrom, of the Karolinska Institute, Stockholm, for the serological typing of the gonococcal strains; Miss J Gedney for excellent technical work; and the medical and nursing staff and health advisers in the Praed Street Clinic for their help. This study was supported by the Medical Research Council and the North West Thames Regional Health Authority.

\section{References}

1 Phillips I. $\beta$ Lactamase producing, penicillin resistant gonococcus. Lancet 1976;

2 Percival A, Corkhill JE, Arya OP, et al. Penicillinase producing gonococci in Liverpool. Lancet 1976;ii:1379-82.

gonorrhoeae in Great Britain 1977-81: alarming increase in incidence and recent development of endemic transmission. Br Med f 1982;285:337-40.

4 McCormack WM. Penicillinase producing Neisseria gonorrhoeae-a retrospective study. $N$ Engl f Med 1982;307:438-9.

5 Birnboim HC, Doly. J. A rapid alkaline extraction procedure for screening recombinant plasmid DNA. Nucleic Acids Res 1979;7:1513-23.

6 Catlin BW. Nutritional profiles for Neisseria gonorrhoeae. Neisseria meningitidis and Neisseria lactamica in chemically defined media and the use of growth requirements for gonococcal typing. F Infect Dis 1973;128:178-94.

Bygdeman S, Danielsson D, Sandström E. Gonococcal W serogroups in Scandinavia. A study with polyclonal and monoc.

8 Sidhu S, Barnes R. Penicillinase-producing Neisseria gonorrhoeae-Los Angeles. Morbidity and Mortality 1983;32:181-3.

9 Easmon CSF, Munday PE, Ison CA, Harris JRW. In vitro and in vivo activity of cefoperazone against Neisseria gonorrhoeae. European fournal of Sexually Transmitted Diseases (in press)

10 Ansink-Schipper MC, Huikeshoven MH, Woudstra RK, et al. Epidemiology of $P P N G$ infections in Amsterdam. Analysis by auxanographic typing and plasmid characterisation. Br $\mathcal{F}$ Vener Dis 1984;60:23-8.

11 Cornmunicable Disease Surveillance Centre. $\beta$ Lactamase producing gonococci, British Isles July-December 1983. Communicable Disease Reports 1984 ; No 9 : 121. 1. RN, Barlow D, Eykyn S, Phillips I. Imported penicillinase producing 364-8.

(Accepted 31 fuly 1984)

\section{Correction}

Combined oral and nasal beclomethasone dipropionate in children with atopic eczema: a randomised controlled trial

In this paper by Dr R J Heddle et al (15 September, p 651) dipropionate was spelt incorrectly throughout. 